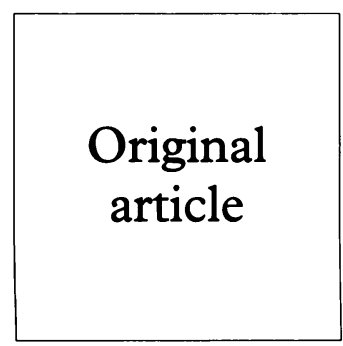

\title{
Behavioural and demographic characteristics of attenders at two genitourinary medicine clinics in England
}

\author{
M Catchpole, N Connor, A Brady, G Kinghorn, D Mercey, B Band, N Thin
}

Objective: To investigate how attenders with sexually transmitted disease (STD) differ from the general population with respect to sexual behaviour, and to identify which attenders at genitourinary medicine (GUM) clinics are at particular behavioural risk for acquiring STD.

Design: Multicentre cross sectional survey.

Setting: Two genitourinary medicine clinics, one in London and one in Sheffield.

Subjects: 20516 patients attending the two clinics over an 18 month period.

Main outcome measures: Behavioural and demographic characteristics and clinical diagnoses were recorded for each patient.

Results: 8862 patients, in whom 12506 diagnoses were made, were seen in the Sheffield clinic, and 11654 patients, in whom 20243 diagnoses were made, were seen in the London clinic. When compared with the reported results from a general population survey, there were higher proportions of clinic attenders reporting two or more sexual partners in the preceding 12 months ( $p<0.001)$, and a higher proportion of males reporting homosexual contact $(13 \%$ compared with $1 \%, \mathrm{p}<0.001)$. Only age and number of sexual partners in the past 12 months were significantly associated with acute STDs for each sex in each clinic. Acute STDs tended to occur with greater frequency in the younger age groups, peaking among 16-19 year olds, particularly among females.

Conclusions: The results have confirmed that patients with STDs exhibit higher risk sexual behaviour than the general population, and have highlighted the problem of continuing high risk behaviour among younger attenders, particularly younger homosexual men. This study has demonstrated that among GUM clinic attenders age and number of sexual partners are key risk factors for the acquisition of an acute STD. The results of this survey also indicate, however, that half of the females and more than one quarter of males with acute STDs reported only one sexual partner in the past 12 months, suggesting that health education messages should point out that it is not only those who have multiple recent sexual partners, or who have recently changed sexual partner, that are at risk of STD, including HIV.

(Genitourin Med 1997;73:457-461)

Keywords: STDs; behaviour; genitourinary medicine clinics

PHLS Communicable Disease Surveillance Centre, 61 Colindale Avenue, London NW6 5EQ

M Catchpole

N Connor

A Brady

Royal Hallamshire

Hospital, Sheffield

$\mathrm{G}$ Kinghorn

Mortimer Market

Centre, London

D Mercey

Guy's and St Thomas's

Hospital Trust,

London

B Band

N Thin

Correspondence to:

Dr M Catchpole.

Accepted for publication

18 June 1997

\section{Background}

Sexually transmitted diseases (STD) remain among the most common causes of infectious disease morbidity in England and Wales ${ }^{1}$ and are identified as a key area for disease reduction in the Health of the Nation white paper. ${ }^{2}$ There has been a shift in the aetiological mix of STDs over the past 20 years, from a predominance of bacterial diseases such as gonorrhoea and syphilis, to viral diseases such as human immunodeficiency virus (HIV) infection, genital herpes, and genital warts. ${ }^{3}$ In addition, there are accumulating data on the widespread distribution of asymptomatic chlamydia infections..$^{4}$ With this shift comes the need to give added emphasis to primary prevention through health education and disease avoidance, rather than mainly rely upon secondary and tertiary prevention through treatment and partner notification. There is growing evidence that to be effective, primary prevention has to be targeted and relevant. ${ }^{6}$ High quality surveillance data, including demographic and behavioural characteristics of patients, are required to inform targeted primary prevention initiatives.
Genitourinary medicine (GUM) clinics in Britain are relatively efficient in selectively attracting members of the population with high risk sexual lifestyles. ${ }^{7}$ Statistical returns (KC60) completed in these clinics represent the major source of information on the frequency and distribution of STDs in England. These returns of aggregate data include information on diagnosis but not on sexual behaviour and risk factors for STD acquisition, other than age, sex and, for some diagnoses, sexual orientation, and do not indicate how many patients have multiple infections, diagnosed either at one visit or over the course of several visits.

This paper describes the first results from a pilot sentinel surveillance study that was developed in response to the need for epidemiological data not provided by routine surveillance mechanisms. The sentinel system is intended to augment existing surveillance data from GUM clinics, providing demographic and behavioural information on individual patient episodes, to inform control and prevention strategies. This paper addresses the questions of: 
Table 1 Data collected for each clinic episode

\begin{tabular}{ll}
\hline (1) & Clinic \\
(2) & Sex \\
(4) & Age groul preference \\
(5) & Ethnic group \\
(6) & $\begin{array}{l}\text { Diagnosis } \\
\text { Number of sexual partners in past year }\end{array}$ \\
(8) & $\begin{array}{l}\text { Sex abroad with someone other than regular } \\
\text { partner in last year and ever }\end{array}$ \\
(9) & $\begin{array}{l}\text { Number of sexual partners (other than } \\
\text { regular partner) abroad in past year }\end{array}$ \\
(10) & $\begin{array}{l}\text { Commercial sex worker } \\
\text { Higher risk sexual partner in past year and } \\
\text { ever (HIV positive, homo/bisexual male, } \\
\text { injecting drug user, commercial sex worker) }\end{array}$ \\
(12) & $\begin{array}{l}\text { Past history of sexually transmitted disease } \\
\text { (either reported by patient or as known by }\end{array}$ \\
attending clinician)
\end{tabular}

(a) how many attenders with sexually transmitted diseases are seen in GUM clinics (compared with how many diagnoses are made),

(b) how attenders with sexually transmitted disease differ from the general population with respect to sexual behaviour,

(c) which attenders at GUM clinics are at particular behavioural risk for acquiring sexually transmitted disease.

\section{Methods}

Three collaborating centres were selected for the pilot, two in London and one in Sheffield. The criteria for selection were: a high clinic attendance rate, willingness to participate in the three year pilot study, and willingness to pilot an electronic data collection system.

The project was coordinated by a steering committee made up of representatives of the collaborating clinics, the Public Health Laboratory Service, and the Department of Health. A core dataset was defined (table 1). The selection criteria for items for the dataset included: validity as indicators of behaviour, consistency with other surveys of sexual behaviour, protection of patient confidential-

Table 2 Characteristics of patients attending the two study clinics

\begin{tabular}{|c|c|c|}
\hline & London & Sheffield \\
\hline Total diagnoses & 20243 & 12506 \\
\hline Total attenders & 11654 & 8862 \\
\hline Attenders with acute STD* & $3839(33 \%)$ & $2421(27 \%)$ \\
\hline Male homo/bisexual attenders-total & 911 & 392 \\
\hline $\begin{array}{l}<25 \text { years } \\
\geqslant 25 \text { years }\end{array}$ & $\begin{array}{l}163(18 \%) \\
748(82 \%)\end{array}$ & $\begin{array}{r}86(22 \%) \\
306(78 \%)\end{array}$ \\
\hline Únknown & 0 & 0 \\
\hline Male heterosexual attenders-total & 5056 & 3985 \\
\hline $\begin{array}{l}<25 \text { years } \\
\geqslant 25 \text { years }\end{array}$ & $\begin{array}{l}1088(22 \%) \\
3961(78 \%)\end{array}$ & $\begin{array}{l}1186(30 \%) \\
2798(70 \%)\end{array}$ \\
\hline Unknown & 7 & 1 \\
\hline Female heterosexual attenders - total & 5527 & 4398 \\
\hline$<25$ years & $1977(36 \%)$ & $1938(44 \%)$ \\
\hline $\begin{array}{l}\geqslant 25 \text { years } \\
\text { Unknown }\end{array}$ & $3534(64 \%)$ & $2458(56 \%)$ \\
\hline \multicolumn{3}{|l|}{ Other exposure } \\
\hline category attenders $\nmid$ - total & 160 & 87 \\
\hline \multicolumn{3}{|l|}{ Ethnic group } \\
\hline White & $6347(54 \%)$ & $7861(89 \%)$ \\
\hline Afro-Caribbean & $4742(41 \%)$ & $566(6 \%)$ \\
\hline $\begin{array}{l}\text { Other/unknown } \\
\text { Ethnic group }\end{array}$ & $565(5 \%)$ & $435(5 \%)$ \\
\hline \multicolumn{3}{|l|}{ Sexual partners in past } \\
\hline 12 months & & \\
\hline $0-2$ & $8754(75 \%)$ & $6829(77 \%)$ \\
\hline $\begin{array}{l}\geqslant 3 \\
\text { Unknown }\end{array}$ & $2900(25 \%)$ & $2025(23 \%)$ \\
\hline \multicolumn{3}{|l|}{$\begin{array}{l}\text { Unknown } \\
\text { Past history of STD }\end{array}$} \\
\hline Yes & $5269(45 \%)$ & $2951(33 \%)$ \\
\hline
\end{tabular}

* See methods for definition of acute STD

†Includes female homosexuals and attenders of unknown sexual preference. ity, feasibility of data collection, and acceptability to patients and clinic staff.

The dataset consists of demographic details, behavioural factors, and diagnostic information. Demographic and diagnostic information is taken from the clinic records systems, while behavioural information is collected on special proformas which are completed by the attending doctor at each new patient episode. All information collected as part of this study is gathered routinely during consultations in GUM clinics. All information was anonymised before transfer to the coordinating centre at CDSC. The chairmen of local research ethics committees were informed of this enhanced surveillance project.

The following diagnoses were classified as "acute STDs" for the purposes of some of the analyses, these diagnoses being most likely to indicate recent acquisition of a sexually transmitted disease through sexual intercourse: infectious syphilis, all gonorrhoea, all chlamydia, first attack of genital herpes, first attack of genital warts, trichomoniasis, antigen positive hepatitis B, non-specific urethritis, scabies, and pediculosis.

Univariate and multivariable analyses of the results were undertaken, using STATA software. ${ }^{8}$ Presence of an acute STD was taken as the dependent variable in the multiple logistic regression analyses. Significant interactions with sex and clinic were found for many risk factors, and therefore separate logistic regression models were also estimated for males and females at the two clinics.

\section{Results}

The results presented are based on the data collected during the first 18 months of the study, during 1995 and 1996, from Sheffield, and from St Thomas's Hospital, London. No data for this period of the study were available from the second clinic in London, owing to relocation and reorganisation of the clinic over this period. The data include information on 8862 patients seen at Sheffield, and 11654 patients seen at St Thomas's Hospital. The patients seen at Sheffield presented with 10176 separate clinical episodes, and were assigned 12506 diagnoses: $67 \%$ of patients were assigned one diagnosis during the study period, $23 \%$ two diagnoses, $8 \%$ three or more diagnoses, and for $2 \%$ no diagnostic information was available. The patients seen at St Thomas's Hospital presented with $15434 \mathrm{sep}$ arate clinical episodes, and were assigned 20243 diagnoses: $49 \%$ of patients were assigned one diagnosis during the study period, $35 \%$ two diagnoses, and $16 \%$ three or more diagnoses. There were 2421 patients who attended the Sheffield clinic and 3839 who attended St Thomas's Hospital with acute STDs during the study period.

The general demographic characteristics of the attenders are described in table 2 . There was a greater proportion of attenders aged 25 years or over at St Thomas's Hospital than at Sheffield ( $72 \%$ compared with $63 \%$, $\mathrm{p}<0.001$ ), a greater proportion of the men at 
Table 3 Comparison of sexual behaviours of all clinic attenders, clinic attenders with an acute STD, and the general population

\begin{tabular}{|c|c|c|c|}
\hline Sexual behaviour & $\begin{array}{l}\text { Attenders with } \\
\text { acute STD }\end{array}$ & $\begin{array}{l}\text { All GUM } \\
\text { clinic attenders }\end{array}$ & $\begin{array}{l}\text { General } \\
\text { population }\end{array}$ \\
\hline \multicolumn{4}{|l|}{$\begin{array}{l}\text { Heterosexual partners in past } \\
\text { year }\end{array}$} \\
\hline \multicolumn{4}{|l|}{ Males $^{\star}$} \\
\hline 0 & $1 \cdot 4 \%$ & $3 \cdot 2 \%$ & $13 \cdot 1 \%$ \\
\hline 1 & $27 \cdot 7 \%$ & $34.9 \%$ & $73.0 \%$ \\
\hline 2 & $29 \cdot 6 \%$ & $29 \cdot 2 \%$ & $8 \cdot 2 \%$ \\
\hline $3-4$ & $23 \cdot 7 \%$ & $20 \cdot 1 \%$ & $4 \cdot 1 \%$ \\
\hline $5+$ & $17 \cdot 6 \%$ & $12 \cdot 6 \%$ & $1 \cdot 5 \%$ \\
\hline \multicolumn{4}{|l|}{ Females* } \\
\hline 0 & $1 \cdot 2 \%$ & $2 \cdot 7 \%$ & $13.9 \%$ \\
\hline 1 & $48.0 \%$ & $53 \cdot 8 \%$ & $79 \cdot 4 \%$ \\
\hline 2 & $30 \cdot 1 \%$ & $26 \cdot 7 \%$ & $4 \cdot 8 \%$ \\
\hline $3-4$ & $14 \cdot 8 \%$ & $11.5 \%$ & $1.6 \%$ \\
\hline $5+$ & $6.0 \%$ & $5 \cdot 3 \%$ & $0.4 \%$ \\
\hline $\begin{array}{l}\text { Proportion of men reporting sex } \\
\text { with another man in past year }\end{array}$ & $9.9 \%$ & $12 \cdot 5 \%$ & $1 \cdot 1 \%$ \\
\hline \multirow{2}{*}{\multicolumn{4}{|c|}{$\begin{array}{l}\text { Proportion of males reporting } \\
\text { more than } 2 \text { heterosexual }\end{array}$}} \\
\hline & & & \\
\hline $\begin{array}{l}<25 \text { years } \\
\geqslant 25 \text { years }\end{array}$ & $\begin{array}{l}46 \cdot 6 \% \\
33 \cdot 4 \%\end{array}$ & $\begin{array}{l}39 \cdot 4 \% \\
25 \cdot 7 \%\end{array}$ & $\begin{array}{r}12 \cdot 6 \% \\
3 \cdot 4 \%\end{array}$ \\
\hline \multicolumn{4}{|l|}{$\begin{array}{l}\text { Proportion of females reporting } \\
\text { more than } 2 \text { heterosexual }\end{array}$} \\
\hline $\begin{array}{l}<25 \text { years } \\
\geqslant 25 \text { years }\end{array}$ & $\begin{array}{l}24 \cdot 9 \% \\
12 \cdot 1 \%\end{array}$ & $\begin{array}{l}20 \cdot 4 \% \\
11 \cdot 1 \%\end{array}$ & $\begin{array}{l}5.5 \% \\
0.9 \%\end{array}$ \\
\hline Contact with commercial sex & & & \\
\hline worker past 12 months ${ }^{\star}$ & $2 \cdot 3 \%$ & $2 \cdot 4 \%$ & $1 \cdot 8 \%$ (last 5 years) \\
\hline Injecting drug use everł & $1 \cdot 4 \%$ & $1 \cdot 7 \%$ & $0.6 \%$ \\
\hline
\end{tabular}

«All GUM clinic attenders differ significantly from the general population, $p<0.001$.

tAttenders aged less than 25 years with acute STD more likely to report three or more sexua partners in the past year than all clinic attenders $(p<0.001)$ or the general population $(\mathrm{p}<0.001)$.

$\neq$ Clinic attenders reported higher rates of injecting drug use than the general population $(\mathrm{p}<0.001)$

Clinic attenders with acute STDs also reported higher rates of injecting drug use than the general population but lower rates than all clinic attenders $(p=0.03)$.

Table 4 Risk factors for acute STDs in GUM clinic attenders: univariate associations between acute STDs and risk factors

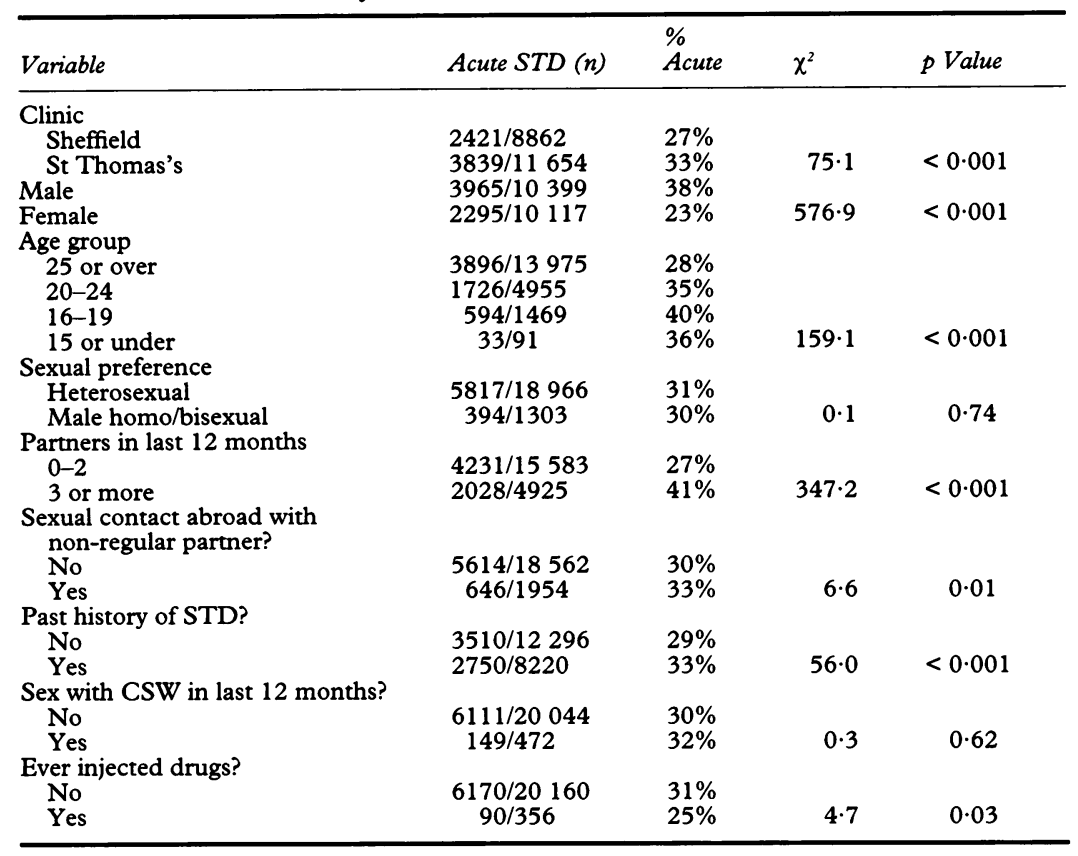

Table 5 Adjusted risk factors for acute STD from multiple logistic regression model for all patients $(n=20482)$

\begin{tabular}{lllll}
\hline Variable & Number & $\begin{array}{l}\text { Odds ratio } \\
\text { (adjusted) }\end{array}$ & $95 \%$ CI & p Value \\
\hline $\begin{array}{l}\text { Clinic } \\
\quad \text { Sheffield }\end{array}$ & 8851 & 1 & & \\
$\begin{array}{l}\text { St Thomas's } \\
\text { Males }\end{array}$ & 11631 & 1.36 & $1 \cdot 27-1.44$ & $<0.001$ \\
\hline
\end{tabular}

Many interactions were found between covariates in the above model. In particular risk factors varied significantly by sex and clinic, so separate logistic regression models were estimated for males and females at the two clinics.

St Thomas's Hospital were homosexual or bisexual (15\% compared with $9 \%, \mathrm{p}<0.001)$, and more were of non-white ethnicity (41\% compared with $6 \%, \mathrm{p}<0.001)$.
All attenders and attenders with acute STDs were compared with the random sample general population surveyed in the national survey of sexual attitudes and lifestyles in 1990 and 1991 (table 3). Attenders at the two clinics in this survey reported more sexual partners in the past 12 months than those in the general population $(p<0.001)$. Almost half of the heterosexual males and one quarter of heterosexual females aged less than 25 years with acute STD reported three or more sexual partners in the past year, compared with $37 \%$ and $19 \%$ respectively in all clinic attenders $(p<0.001)$ and $13 \%$ and $6 \%$ respectively in the general population $(\mathrm{p}<0.001)$. A much higher proportion of men attending the clinics reported sexual contact with another man in the past 12 months than was reported in the general population survey (13\% compared with $1 \%, \mathrm{p}<0.001)$. Contact with commercial sex workers in the past year was reported by $2.3 \%$ of clinic attenders compared with the general population rate of $1.8 \%$ in the past 5 years $(p<0.001)$. Clinic attenders reported higher rates of injecting drug use than the general population $(1.7 \%$ compared with $0.6 \%$, $\mathrm{p}<0.001)$. Clinic attenders with acute STDs also reported higher rates of injecting drug use $(1 \cdot 4 \%)$ than the general population $(0.6 \%)$ but lower rates than all clinic attenders $(1 \cdot 7 \%$, $\mathrm{p}=0.03$ ).

The results of univariate analysis of the association between acute STD and various risk factors are presented in table 4 . The following factors were found to be strongly associated with presence of an acute STD: attendance at St Thomas's Hospital rather than Sheffield, male sex, younger age, reporting three or more sexual partners in the past 12 months, and past history of STD. In addition, a weaker association was found between sexual contact abroad with a non-regular partner and presence of an acute STD. Risk of having an acute STD did not vary significantly with sexual preference (heterosexual versus male homo/bisexual), and a history of injecting drug use was associated with a decreased risk of acute STD.

In the multiple logistic regression model for all attenders combined males were twice as likely as females to have an acute STD, and attenders at St Thomas's Hospital were more likely than those at Sheffield to have an acute STD (table 5). In the separate multiple logistic regression analysis models for males and females at each of the two clinics, only age and number of sexual partners in the past 12 months were significantly associated with acute STD for each sex in each clinic (table 6). Acute STDs tended to occur with greater frequency in the younger age groups, peaking in the 16-19 year olds, particularly among females. A history of three or more sexual partners in the past 12 months was more strongly associated with acute STD for males than for females at each clinic. In the regression analysis, male heterosexuals were at higher risk of having an acute STD than were male homo/bisexuals attending each clinic. Acute STDs were associated with a history of 
Table 6 Adjusted risk factors for acute STD in males and females for St Thomas's and Sheffield separately

\begin{tabular}{|c|c|c|c|c|c|c|c|c|}
\hline \multirow[b]{3}{*}{ Variable } & \multicolumn{4}{|c|}{ St Thomas's } & \multicolumn{4}{|c|}{ Sheffield } \\
\hline & \multicolumn{2}{|c|}{ Males $(n=6008)$} & \multicolumn{2}{|c|}{ Females $(n=5623)$} & \multicolumn{2}{|c|}{ Males $(n=4377)$} & \multicolumn{2}{|c|}{ Females $(n=4474)$} \\
\hline & $O R$ & p Value & $O R$ & p Value & OR & p Value & $O R$ & $p$ Value \\
\hline \multicolumn{9}{|l|}{ Age group } \\
\hline$\geqslant 25$ & & & 1 & & 1 & & 1 & \\
\hline $20-24$ & $1 \cdot 27$ & & 1.66 & & 1.43 & & $2 \cdot 45$ & \\
\hline $16-19$ & 1.55 & & $2 \cdot 86$ & & $1 \cdot 30$ & & $3 \cdot 51$ & \\
\hline$\leqslant 15$ & 0.94 & $<0.001$ & $2 \cdot 52$ & $<0.001$ & $1 \cdot 52$ & $<0.001$ & 2.96 & $<0.001$ \\
\hline \multicolumn{9}{|l|}{ Sexual preference } \\
\hline $\begin{array}{l}\text { Heterosexual } \\
\text { Male homo/bisexual }\end{array}$ & $\frac{1}{0.49}$ & & 1 & & $\begin{array}{l}1 \\
0.50\end{array}$ & & 1 & \\
\hline Other ${ }^{\star}$ & 0.92 & $<0.001$ & 0.63 & 0.09 & $1 \cdot 14$ & $<0.001$ & 0.44 & 0.01 \\
\hline $\begin{array}{l}\geqslant 3 \text { partners in } \\
\text { past } 12 \text { months }\end{array}$ & & & & & & & 1.26 & 0.01 \\
\hline Sex abroad & 1.08 & 0.36 & 0.59 & 0.002 & 0.94 & 0.57 & 0.84 & 0.21 \\
\hline Past STD & 1.62 & $<0.001$ & $1 \cdot 12$ & 0.11 & $1 \cdot 16$ & 0.04 & 1.04 & 0.59 \\
\hline \multirow{2}{*}{$\begin{array}{l}\text { Sex with CSW } \\
\text { past } 12 \text { months }\end{array}$} & & & & & & & & \\
\hline & 0.56 & $<0.001$ & $1 \cdot 19$ & $0 \cdot 77$ & 0.55 & 0.05 & 0.54 & 0.42 \\
\hline Injected drugs & $0 \cdot 58$ & 0.006 & 0.79 & $0 \cdot 50$ & $0 \cdot 82$ & $0 \cdot 38$ & $0 \cdot 76$ & 0.41 \\
\hline
\end{tabular}

previous STD among men but not among women in each clinic. Men in each clinic who reported contact with a commercial sex worker in the previous 12 months were significantly less likely to have an acute STD than were those who did not report this risk factor. There was also a lower risk at St Thomas's Hospital, but not at Sheffield, of acute STD among men who had ever injected drugs, compared with those that did not give such a history. Women from St Thomas's Hospital who had had sex with a non-regular partner abroad in the past 12 months were less likely than other women from St Thomas's Hospital to have an acute STD. No association was observed between this risk factor and acute STD among men at St Thomas's Hospital or among men or women at Sheffield.

The percentage of attenders reporting three or more sexual partners was highest among homo/bisexual males ( $61 \%$ at St Thomas's Hospital, $50 \%$ at Sheffield), lower among heterosexual males $(31 \%$ at St Thomas's Hospital, $27 \%$ at Sheffield), and lowest among heterosexual females $(13 \%$ at St Thomas's Hospital, $17 \%$ at Sheffield) (table 3). At both clinics, attenders aged less than 25 years were more likely to report three or more sexual partners in the past 12 months $(29 \%$ in both clinics) than were older attenders $(23 \%$ at $\mathrm{St}$ Thomas's Hospital, $19 \%$ at Sheffield). The highest proportion of attenders reporting three or more sexual partners in the past 12 months was seen among young homo/bisexual men in both clinics.

A higher proportion of homo/bisexual male attenders than heterosexual male attenders were tested for HIV infection (46\% compared with $30 \%$, OR 1.95, p < 0.001). Furthermore, a higher proportion of homo/bisexual males than heterosexual males tested for HIV infection were recorded as not having an STD (acute or otherwise) at the time of testing (70\% compared with $58 \%$, OR 1.50 $\mathrm{p}<0.001$ ).

At Sheffield, sexual intercourse abroad with a non-regular partner during the previous 12 months was reported by $17 \%$ of homo/bisexual males, $10 \%$ of heterosexual males, and $8 \%$ of heterosexual females (table 5). At St
Thomas's Hospital, sexual intercourse abroad with a non-regular partner during the previous 12 months was reported by $23 \%$ of homo/ bisexual males, $12 \%$ of heterosexual males, and $6 \%$ of heterosexual females.

\section{Discussion}

The pilot survey has produced a unique dataset based on over 20000 patients at two large GUM clinics, one in London and the other in the middle of England. The survey has provided a more detailed picture of the distribution of infections and sexual behaviour among patients attending GUM clinics than is available from existing routine surveillance data. The results have demonstrated that patients with STDs exhibit higher risk sexual behaviour than the general population, and have highlighted continuing high risk behaviour among younger attenders, particularly younger homosexual men. It should be noted that because there is considerable variation in the demographic and behavioural $\mathrm{mix}$ of attenders at different GUM clinics, particularly in London, the data from St Thomas's Hospital cannot be interpreted as representative of all London clinics. It is also the case that the general population survey used as a comparator for this study was conducted in $1990-1$, but it is highly unlikely that any changes in the frequency and distribution of sexual behaviour between then and 1995-6 will have been of such magnitude as to affect the significance of differences between the general population and clinic attenders as reported in this study.

This study has demonstrated that among GUM clinic attenders age and number of sexual partners are key risk factors for the acquisition of an acute STD. The results also suggest that among male GUM clinic attenders homo/bisexual sexual preference, contact with a commercial sex worker in the past 12 months, and history of injecting drugs (at St Thomas's Hospital but not at Sheffield), are associated with a reduced risk of acquisition of an acute STD. These observations may reflect some reporting bias due to normative pressures on attenders, in the face of HIV prevention mes-

,

.

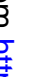


sages, not to admit to such behaviours. The results might also indicate that attenders reporting these behaviours more frequently adopt sexual practices that reduce the risk of transmission of STDs, such as the regular use of condoms. An alternative explanation could be that men reporting homo/bisexual sexual preference, contact with a commercial sex worker in the past 12 months, or history of injecting drugs, and women who have had a recent sexual partner abroad are more likely to attend for routine screening for HIV or other STDs, in the absence of symptoms. Some evidence for this comes from the observation in this study that the proportion of attenders who were tested for HIV infection but did not have an STD ("acute" or otherwise) was higher among homo/bisexual males than among heterosexual males.

Past history of STD was found to be a risk factor for acquisition of an acute STD among males but not among females attending the two clinics. This association may reflect differences in behaviour between males with a past history of STD and those without such a history, or may reflect differences in the prevalence of STDs in the sexual networks within which different groups of clinic attenders interact. In either case, the results suggest that there is scope for further reduction in STD incidence through counselling of patients.

The results indicate high levels of behaviour among some homo/bisexual males likely to put them at continued risk of HIV transmission. At least $50 \%$ of the homo/bisexual males aged under 25 years attending the two clinics reported having had three or more sexual partners in the UK during the previous 12 months. The type of sexual contact between homo/bisexual males and their partners was not recorded in this study, and therefore the proportion of contacts that were limited to encounters within which only safe sex was practised is not known. The risk of acquisition of an acute STD was, however, significantly associated with higher numbers of sexual partners for homo/bisexual males, suggesting that in many cases unsafe sex was practised. The high proportion of homo/bisexual men reporting sexual contact abroad with a non-regular partner also gives cause for concern, and warrants further investigation into where these contacts are occurring and from where the sexual partners originate, and may indicate a need for health promotion intervention.

Johnson et al have recently demonstrated that the sexual behaviours of attenders at GUM clinics differed markedly from those of non-attenders. ${ }^{7}$ They also noted that at a population level clinics only see a minority of those reporting risk markers for STD transmission. This study has similarly demonstrated that, taken as a whole, attenders at GUM clinics report behaviours likely to place them at risk of exposure to an STD more frequently than the general population, and that for patients with acute STDs the rates of partner acquisition appear to be higher still. The results of this survey also indicate, however, that the majority of heterosexual attenders with acute STDs at each clinic reported no more than two partners in the past 12 months. Half of the females and more than one quarter of males with acute STDs reported only one sexual partner in the past 12 months, and as such may not be perceived either by themselves or by health service providers, as being at particular risk for acquiring an STD, including HIV. This finding suggests that health education messages should point out that it is not only those who have multiple recent sexual partners, or who have recently changed sexual partner, that can be at risk of STD.

This project was funded by the Department of Health. The steering committee are grateful to all staff in the collaborating clinics for the time and effort devoted to setting up and running the project.

1 Catchpole M. Sexually transmitted diseases in England and Wales: 1981-1990. Communicable Disease Report 1992;2: R1-7.

2 The Health of the Nation: a consultative document for health in England. Cm 1523. London: HMSO, 1991

3 Department of Health. New cases seen at NHS genitourinary medicine clinics in England: 1995 annual figures. London, DoH, SD2B, 1996.

4 Dryden MS, Wilkinson M, Redman M, Millar MR Detection of Chlamydia trachomatis in general practice urine samples. Br $\mathcal{F}$ Gen Pract 1994;44:114-7.

5 Zelin J, Robinson AJ, Ridgway GL, Jones E, Williams P. Chlamydia urethritis in heterosexual men attending genito-urinary medicine clinic: prevalence, condom usage and partner notification. Int $\mathcal{f} S T D$ AIDS 1995;6:27-30.

6 Toomey KE, Moran JS, Raffertey MP, Beckett GA Epidemiological considerations of sexually transmitted diseases in underserved populations. Infect Dis Clin N Am 1993;7:739-52

7 Johnson AM, Wadsworth J, Wellings K, Field J. Who goes to sexually transmitted disease clinics? Results from a national population survey. Genitourin Med 1996;72 197-202.

8 Stata Statistical Software: Release 5.0 College Station. TX, USA: Stata Corporation, 1977. 